and within each subject alphabetically by authors (Catalogue Collectif des Livres Français de Sciences et T'echniques, 1960-1962. Pp. xiv + 146. Paris: Groupe des Editeurs de Livres Français de Sciences et de Tech. niques, c/o Syndicat National des Editeurs, 117 Boulevard Saint-Germaine, 1963). There is an author index and an alphabetical subject-word index. Prices quoted are those current in France on September 1, 1963.

\section{Building with Concrete Blocks}

This is the title of No. 7 of the Advisory Note series recently published by the Cement and Concrete Associatjon, which sets out to show that concrete blocklaying is a quicker way of building a wall than bricklaying (Pp. 23. London: Cement and Concrete Association, 1963). It achieves its object in a most practical manner, and if the advice given is followed, both as regards materials and manipulation, even an amateur cannot go far wrong. For many purposes light-weight conerete blocks possess many advantages compared with building bricks. The former are usually manufactured to standard dimensions with an 18 in. $\times 9$ in. face; thus one 4 -in. thick block is equivalent to 6 bricks and a 9 -in. thick block to 12 bricks. This means that there is considerable economy in time in building a wall with concrete blocks compared with the same construction in brickwork. Further, there is a saving of more than 60 per cent on the amount of mortar required for a wall of the same thickness. Other claims for this type of block are that it possesses high thermal insulation value, high fire resistance, nails and screws can be directly driven into it, and as a building unit it is easy to cut if necessary, likewise easy to handle before and during laying. There are various types of concrete blocks available depending on the purpose in view; light-weight blocks lend themselves to internal walling not subject to heavy loads; denser blocks are recommended for higher strength and heavy loads, and also for external walls. A further choice lies in selection of one or other of three types: solid blocks, embodying dense or light-weight aggregate, which may also be aerated; hollow blocks which have the cavities going right through; and cellular blocks, where the cavities do not go right through but are laid with the openings downwards giving a full bed-face on top for mortaring. This handbook gives details on storage and handling of conerete blocks, specifications for suitable mortar, advice on laying of blocks, facing work, protection, etc. It is well illustrated and produced and has the further merit of avoiding unnecessary technicalities. Copies are available free of charge from the Cement and Concrete Association, 52 Grosvenor Gardens, London, S.W.1.

\section{Flint Tools from Southern Arabia}

Even as long ago as Lower Palæolithic times, differing cultures flourishing in different parts of the world can be distinguished. For example, the makers of coups-de-poing, or handaxes, lived throughout the area from Western Europe to South Africa and also in Southern India, but their tools do not occur in any numbers east of the Rhine or in South East Asia. In these regions other cultures held sway and fashioned their own characteristic implements. The lines of demarcation, however, are never rigid; overlapping occurs, and the finding of the type tool of one culture in what, theoretically, should be the home of another is always of great interest. Thus, coups-de-poing occur in Palestine but are very rare further north, and, just as one swallow does not make a summer, the occurrence of a few such tools in Asia Minor does not mean that Acheulean man seriously occupied that region. A surface collection of flints from Habarat in South Arabia is deseribed in the December 1963 issue of Man by Joan Crowfoot Payne, of the Ashmolean Museum at Oxford, and Stewart Hawkins, the finder, and is of considerable interest, including, as it does, a couple of Acheulean ovates. Habarat is an oasis 70 miles north- north-west of Ras Dharbat Ali, a headland in the centre of the South Arabian coast. Flint tools were collected from a site not far from a spring. The two handaxes were found together on a flat hilltop overlooking the wadi; the other group of flints would appear to belong to later industries and include knives, tanged arrow-heads, leafshaped points, scrapers and flakes. Handaxes have been found, though rarely, elsewhere in South Arabia, for example, by Dr. Henry Field, but the two in question can also be compared with a fine series from the oasis of Kharga to the west of the Nile, discovered and published by Dr. Caton-Thompson.

\section{Action of Trypsin}

C. Roby, M. Charsaigne and J. P. Leroux have recently investigated the mode of action of trypsin on the three stages of coagulation (Hemostase, 3, No. 3; 1963). The coagulant action of trypsin is neither thrombin-like nor thromboplastin-like: it is probably explained by a widespread activation of coagulation factors. This activation only occurs in the presence of calcium and is sensitized by the addition of eephalin. A quantitative relationship exists between the percentage of adsorbable factors and the coagulation time of a system consisting of: trypsin, calcium, cephalin, adsorbed bovine plasma and dilutions of the plasma under test for variable content of adsorbable factors. This quantitative relation has been verified by using artificial mixtures and Christmas disease plasma. The authors show that the 'trypsin time' thus defined makes it possible to estimato the percentage of adsorbable factors ( $K$-test) which simultaneously takes into account the factors of the prothrombin complex and factor IX. Attention is directed to the suitability of this ' $K$-test' for the control of anticoagulant treatment by anti-vitamin $K$ drugs and for rapid distinction between deficiencies of factors XIII and IX.

\section{Malaria Terminology}

In 1953 the World Health Organization published a terminology of malaria in English, followed one year later by the French text. It was widely welcomed as a valuable guide through the intricacies of malaria terminology and a help towards rendering it uniform throughout the world. In the ten years that have elapsed since its publication the malaria situation has greatly changed. Chemotherapy has made considerable advances. Knowledge of the mosquito vectors has increased greatly, in part stimulated by the appearance of resistance to various insecticides, with the threat that this entails. Active research on new insecticides is in progress and holds some promise. These developments are closely linked with the principal change: the almost world-wide conversion of malaria control into malaria eradication. The latter concept has led to the introduction of new epidemiological and operational concepts and, consequently, terms. The need for a new approach to malaria terminology has been increasingly felt in the past few years, both to incorporate the new concepts and to bring the previous terminology up to date where it has been superseded by newer knowledge. This work has been undertaken by a World Health Organization Drafting Committee composed of Dr. A. Gabaldon, Ministry of Health and Social Welfare, Venezuela, Profs. P. C. C. Garnham and G. Macdonald, London School of Hygiene and Tropical Medicine, and Dr. E. J. Pampana, University of Rome (Terminology of Malaria and of Malaria Eradication. Report of a Drafting Committee. Pp. 127. Geneva: World Health Organization; London: H.M.S.O., 1963. $12 \mathrm{Sw}$. franes; 20s.; 4 dollars).

\section{The Geological Society of London: Awards}

The following awards for 1964 have been made by the Geological Society of London: Wollaston Medal, to Sir Harold Jeffreys, formerly Plumian profossor of astronomy in the University of Cambridge, for his outstanding contributions to the science of geophysics; Lyell Medal, to Dr. 